The Geneva Papers on Risk and Insurance, 17 (No. 64, July 1992), 355-361

\title{
The Past and Future of Loss Financing
}

\author{
by James V. Davis, Ph. D.*
}

One of the major changes in risk management in the 1970s and 1980s has been the evolution of loss financing. Prior to these two decades, risk managers' responsibilities ordinarily had entailed risk identification and assessment, design of coverages to fit the risks identified, and input into the loss control and loss prevention process. Expected losses, if such a number had been specified, were normally transferred to insurance companies. For the first two thirds of this century, risk managers were buyers of insurance for the most part instead of individuals who chose among competing loss financing program designs.

There always have been exceptions, of course. For years prior to these two decades, multinational firms had utilized captive insurance companies to structure and retain a portion of their global property risks. Other coverages might be included as needed. But the majority of non-property risks were transferred to insurance companies.

A change in cost in the mix of exposures resulted in changes in how the insurance buying dollar was applied. Instead of being primarily property risks in premium terms, many firms, particularly in the United States, observed that expenditures for workers compensation, automobile liability, general liability, products liability, directors and officers liability and other non-property coverages were responsible for most of their insurance costs.

The change to being predominantly casualty risks was accompanied by an increasing emphasis by underwriters on the individual loss ratios of their insureds. As larger insureds discovered that, rather than being part of a large pool of risks, their premiums were largely a function of their own losses, they began to search for alternatives to guaranteed cost and incurred loss retro policies. The knowledgeable risk manager wanted to reap the benefit of favorable loss experience for his or her company.

The combination of significant casualty premiums and losses and individual loss rating caused risk managers a number of concerns. First, they recognized that often they were trading dollars with insurance companies. Sufficient funds had to be transferred to underwriters so that claims payments could be made. In the process, the insured absorbed

\footnotetext{
* Chairman and Chief Executive Officer, Advanced Risk Management Services.
} 
a variety of friction costs (insurer's profit and administration, brokerage commissions, etc.). If it were possible to avoid dollar trading initially, some of the friction costs could be avoided and/or decreased.

Another consideration was the length of time that funds were held by insurers before being used to pay losses in the insured's behalf. In certain casualty lines, underwriters might hold the insured's premiums for 10 years or more before paying out the last claim dollar associated with a particular policy year. During these years, it was the underwriters, not the insured, who earned substantial investment income on the loss reserve dollars. Risk managers, with the assistance of their brokers, independent risk management consultants, and selected underwriters, set about to change the situation.

As a result of their collaborative efforts, risk managers soon had an array of alternative loss financing plans from which to choose. The better plans achieved the twin goals of cutting friction costs and recouping investment income.

In order to optimally utilize the new plans, risk managers had to develop new data bases and to assess previously available data in new ways. A loss financing decision-making matrix had to be created to help risk managers select from among different program configurations.

Since the intent of many of the new plans was to allow insureds to retain their predictable losses, risk managers required accurate summaries of their losses so that one-point estimates of future losses could be developed. Since final plan costs often were a function of actual losses, an idea of the variability of losses around the one-point estimate also was needed. Some programs were more desirable at one loss level, others at another. The adaptation of probability distributions to risk management addressed the latter need.

The growth of loss financing contributed to the growth of a variety of support services. The latter include:

- Actuarial services;

- Claims management;

- Loss prevention services;

- Risk management consulting, and

- Risk management information systems.

Some risk managers wanted access to all or some of these services on an unbundled basis so that various firms unrelated to their underwriters could be employed. Certain underwriters responded to this demand, oftentimes grudgingly, while at least one underwriter, American International Group (AIG), capitalized on it as part of a conscious strategy.

Several key decision-making variables were identified to help risk managers select the least cost plan that best fit their firms. These included the firm's discount rate, tax position, cash position, willingness to assume non-operational risk, etc. A summary of some of these important considerations will help to illustrate the complexity of the decision-making process.

(1) Discount Rate: An organization's discount rate (hurdle rate, cost of money, cost of capital) is key because it indicates the alternative returns that can be earned by investing free cash internally. A firm with a higher discount rate will typically want a cash flow program more than a firm with less attractive uses for its funds. 
(2) Tax Rate: An insured's tax rate and tax posture will influence its choice of loss financing programs. Organizations which pay no taxes (governmental entities, other nonprofits) will have a strong bias for self-insurance. Such organizations get no benefit from the ability to deduct loss reserves for tax purposes implicit in some premium payments. Thus, if the organizations are large enough to have predictable losses and financially strong enough, they will select self-insurance.

A simple illustration will demonstrate why. Assume an organization has $\$ 3$ million in loss costs and associated expenses. If all of the $\$ 3$ million is deductible for tax purposes, note the effective cost of the payout to organizations in different effective tax brackets.

\begin{tabular}{lccccc} 
& \multicolumn{5}{c}{ Tax Bracket } \\
& 0 & $10 \%$ & $20 \%$ & $30 \%$ & $40 \%$ \\
\cline { 2 - 6 } $\begin{array}{l}\text { Effective Cost } \\
\text { (in millions) }\end{array}$ & $\$ 3.0$ & $\$ 2.7$ & $\$ 2.4$ & $\$ 2.1$ & $\$ 1.8$
\end{tabular}

This table shows why zero-basis taxpayers, individually or collectively, will seek to retain losses, while firms with higher tax rates would like to be able to deduct present and future loss costs currently.

Risk managers are given a standard admonition not to select a particular loss financing plan for tax reasons. The history of what has happened to previously perceived tax-favored plans lends support to this point of view. Self-insurance reserves, paid-loss retros, and single parent captive insurance companies have been viewed as defensible plans for deduction of reserves during the last 15 years. None are perceived that way today.

Nevertheless, a risk manager must be aware of the firm's tax position and tax posture. Some firms are very aggressive on tax issues and will seek short-term advantages even in the face of data that suggest that longer term the plan will not survive close scrutiny by tax authorities. There are, however, far fewer firms today as compared to 10 years ago that are aggressive on insurance issues.

(3) Cash Position: A firm's cash position is also influential in plan selection. An organization which has limited liquid assets will more likely consider loss financing programs that allow it to retain cash inside the firm. This is why corporations struggling with large amounts of debt, e.g., leveraged buyouts (LBOs), most often choose self-insurance, deductible or paid-loss retro plans. Even these choices are far from optimal for a LBO since each requires some form of security. For a LBO, a dollar of cash and a dollar letter of credit are often equivalent since each serves to diminish a limited pool of cash and credit.

While firms with strong cash positions often will also choose to use the above programs, they also have available to them the whole array of retrospectively-rated plans, captive insurance companies, and rent-a-captive vehicles. Many of these programs require that cash physically be shifted to an insurer or separate corporate subsidiary. This makes sense only if free current assets exist.

(4) Non-Operational Risk: One of the major changes in loss financing in the last five years has been the greater willingness of firms to retain a portion of their catastrophic losses in addition to their predictable losses. One firm retains at least $\$ 1$ million per occurrence for all of its different casualty coverages, the first $\$ 5$ million of each property 
loss, and the first $\$ 25$ million of each general liability loss including products. It is no longer unusual to find organizations with significant products exposures accepting the first $\$ 25$ million of loss internally.

To accept such retentions, a firm must consider potentially uninsured catastrophic losses in the same way it responds to unforseen problems in its business operations. Some companies, however, believe they assume enough risk in their business operations, and if some fortuitous losses can be transferred to an insurance company at a reasonable price, the transfer should be made. One extremely profitable Fortune 100 company, for example, regards an uninsured loss of $\$ 10$ million as unacceptable. This firm emphasizes growth in earnings per share and does not want its EPS growth curve impacted by events against which insurance would have provided protection.

Given the general trend toward greater assumption of risk by organizations, it is not surprising that a variety of quantitative models have been developed to help risk managers assess how much risk should be assumed. The better of these models highlight the interrelationships between risk management and financial objectives.

There are other variables that affect the loss financing decision-making process. The four described should give the reader a feel for the decision-making process.

As has been suggested, risk managers have a variety of options from which to choose. Descriptions of some of the major loss financing alternatives will help convey the intent of all of the plans.

- Self-Insurance: Individual states permit organizations to self-insure their workers compensation and automobile liability exposures. Self-insurance taxes are imposed in lieu of state premium taxes and collateral is required, often in the form of a surety bond. The self-insurer retains the funds needed to pay its predictable losses until the losses actually are paid.

The self-insurer may purchase specific excess insurance to limit its financial exposure to any one loss. Aggregate insurance, unlikely to be available at a reasonable price, would offer protection against an accumulation of losses within the per occurrence retention.

- Self-Insured Retentions (SIRs) / Deductibles: The insured can establish a self-insured retention and buy excess insurance above it or establish a deductible as part of an overall policy limit. The latter program is used for automobile liability, general liability and property programs, and recently, for workers compensation.

Matching deductible programs are popular with larger corporations for their liability exposures. In a matching deductible program, the deductible is set equal to the policy limit; funds are retained internally but since an insurance policy is in force, evidence of insurance can be provided to third parties.

The need for insurance policies from admitted insurance companies for workers compensation and automobile liability or the need to provide evidence of insurance to businesses dealing with the insured provide many of the ties that large firms have to their insurers. The relaxation of those requirements would lead to a sharp reduction in premiums flowing to admitted companies.

- Retrospectively-Rated Plans: There is a family of retrospectively-rated plans whose purpose is for the insured to ultimately pay its own losses within a range established by the 
minimum and maximum premiums called for in the policy. Losses are subject to a per occurrence limitation. A policy year remains open for a number of years resulting in additional or return premiums depending on the insured's loss experience.

Retros vary in their loss financing effectiveness. Incurred loss retros require the insured to pay the estimated ultimate premium to the underwriter, ordinarily during the first policy year. An improved version of the incurred loss retro, the investment credit retro, allows the insured to receive the investment income being earned on its loss reserve dollars.

Prior to the development of deductible plans for workers compensation, the paid-loss retro was the insurance industry's response to having its larger customers file for qualified self-insurance. Premium payments again are adjustable within a band, but the insured holds the loss dollars until losses are paid.

The continued use of retros for workers compensation is in question because of the residual market loads attached to these programs. Residual market loads are the charges the carriers make to try to recapture a portion of the losses they are suffering in state workers compensation assigned risk pools. Since at least in the short term, the residual market loads can be avoided through use of self-insurance and deductible plans, insureds increasingly are opting for self-insurance wraparound plans in which elements of each are combined through a common service provider.

There are virtually endless permutations off of the incurred loss retro. For purposes of this discussion, the compensating balance retro, early close retro, and loss multiplier plans have been ignored.

- Captive Insurance Company; Rent-A-Captive: Discussion of captive insurance companies can be traced back to the earliest part of this century. There are several thousand captives in various domiciles around the world.

Historically used to rationalize the global property programs of multinational corporations, captive formations were spurred by the hard markets of the 1970s and 1980s. In those years, many casualty captive insurance companies were formed. Subsequent disallowance by the Internal Revenue Service of tax deductions for premium payments to single parent captives, a position sustained in a series of court decisions where no substantial amounts of outside business were present, has muted that growth. An extended soft market has had the same effect. Nevertheless, single parent captives continue to be formed to insure the global property/casualty exposures of multinationals and to insure various specialty lines.

Captive insurance companies can act either as reinsurers of admitted insurance companies when admitted paper is required or as direct writers. In either mode, one of the attractions of a captive for a risk manager is that it provides a dedicated source of funding for retained losses. In an international setting, a captive can still be a useful transfer pricing mechanism.

Rent-a-captives are what the name implies, a captive rented from a third party usually so the insured can avoid the necessity of capitalizing its own company. They are usually available for reasonable fees and, on balance, tend to fulfill the needs of companies below the Fortune 500.

There also has been widespread use of captives by groups and associations seeking the cash flow benefits and economies of scale in service costs they cannot achieve individually. Properly put together; group programs can yield meaningful savings. 
- Excess Plans: Loss financing plans also can be designed for excess coverages, particularly first layer excess. These plans go by different names such as banking excess, chronological stabilization, or swing plans. They can be pre-funded or post-funded. Each seeks to smooth the cash flow impact of a retained excess loss on the insured. In a post-funded plan, for example, this can be achieved by the insurer paying the excess loss and then being reimbursed by the insured over a period of three to seven years. A stipulated interest rate is charged for the advancement of funds.

The smoothing of cash flow is not the only objective. Another major goal is to smooth the impact of the loss on the income statement. Such plans must be carefully structured to achieve this goal. An important element in achieving the objective is whether the plan contains any true insurance risk. If not, the "premium" probably will be treated as a deposit.

This brief survey of loss financing plans has concentrated on those widely available in the United States. The number of plans accessible by risk managers in other parts of the world are smaller in number because there is less need for the diversity that exists in the U.S.

In many of the developed countries, workers compensation and/or automobile liability are provided by the state. General and products liability losses are less prevalent and do not lead to the same sort of court awards. Thus, property insurance premiums are the major cost, and property insurance is not as susceptible to cost reduction by the use of loss financing techniques.

Deductibles and swing plans can be used for property. Captive insurance agencies are formed, e.g., in Germany, to help offset the impact of tariff-rated premiums. Numerous captive insurance companies have been formed by Australian, European, and Japanese parents.

As some forms of casualty losses assume greater importance in the future (products liability losses in the EEC), new or adapted loss financing plans will be utilized. Paid-loss retros already are available in the United Kingdom.

In the future, loss financing will diminish in relative importance in the United States at the same time that it is growing in importance in the remainder of the world. In the U.S., loss financing has concentrated on recapturing investment income and squeezing the last point out of the 15-25 per cent of the premium dollar spent on administrative and intermediary services. Most of those savings have been attained.

The challenge now for risk managers is to make good on the often unrealized potential to prevent losses and to mitigate the impact on the firm of those losses that cannot be prevented. There are a number of obstacles to realizing this potential, but they must be faced if risk management is to continue to grow in stature.

One of the most important of the obstacles is that loss control personnel often report to operations management instead of the risk manager. Loss control personnel should report to the risk manager, who must then be seen to be developing creative solutions to stem the outflow of loss dollars.

Credibility with senior management will be of paramount importance. The risk manager will need to enlist the ongoing support of top-level managers if a sustained loss control program is to be effective. If risk managers cannot accomplish putting wide-ranging, successful 
loss control programs in place, it will be more difficult for them to expand their horizons into all facets of corporate risk as some observers of risk management believe they should.

Organizations will continue to expand their retentions. Many large companies now understand that they have larger net worths than the insurers with whom they do business; such companies will choose to hold ever more risk internally.

Premium volatility will remain a problem. Insurance is a product intended in part to stabilize the effect of unforseen events on financial statements; instead, it has become a source of substantial instability itself in hard markets. The availability of better data allows insurers to pinpoint problem lines more quickly than in the past. This may help to avoid another wrenching adjustment in premiums.

Two changes that will impact the loss financing strategies of U.S. risk managers are 24hour coverage and the likely advent of some sort of nationalized medicine. The former coverage will provide insurance for around-the-clock medical costs whatever their cause. Where used, such covers should help to reduce the cost shifting between employee benefit medical plans and workers compensation, reduce duplicate billings between the two programs, etc. Several carriers now are filing their 24 -hour coverage plans with state regulators.

Longer term, it is unlikely that the United States will continue to devote an increasing percentage of its Gross National Product to health care costs. By the end of this century, some version of national health care is likely to be in place. The impact that will have on medical plans and workers compensation is clear.

Elsewhere in the world, loss financing should expand in importance. As more countries adopt rigid environmental standards, toughen products liability laws, demand a higher level of conduct from officers and directors, risk managers will have more loss financing issues with which to deal. As global insurance programs increase in popularity, their use will help to speed the spread of sophisticated approaches. 